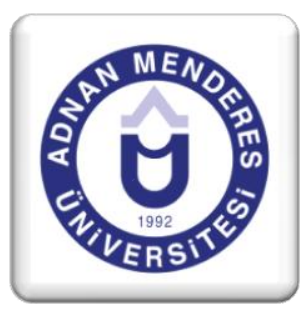

\title{
TV Dizilerinin Destinasyon İmajı Üzerine Etkisi
}

\section{The Effect of TV Series on Destination Image}

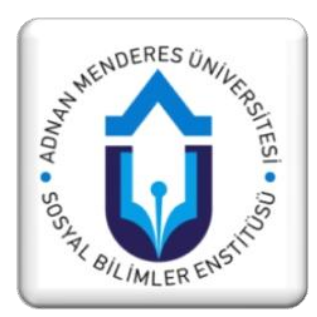

Fatma ÇAKIR $^{1}$

\section{Özet}

Son dönemde sayıları artan televizyon dizileri ve bu dizilere turistik bir ürün olarak yerleştirilen destinasyonlar, izleyicilerin algıladığı destinasyon imajı üzerinde etkili olmaktadır. Bu dizilerin çekildiği destinasyonlara yönelik olumlu bir marka imajının yaratılması ve güçlendirilmesi, şehir turizmi açısından da oldukça önemlidir.

Bu çalışmanın amacı televizyon dizilerinin, izleyicilerin algıladıkları destinasyon imajı üzerindeki etkisini belirlemektir. Çalışma aynı zamanda Aydın il merkezinde yaşayan 18 yaş üstü TV dizisi izleyicisi kişilere yönelik bir anket çalışmasını içermektedir. Çalışmada, anket verileri kullanılarak çeşitli istatistiki analizler yapılmıştır. Yapılan analiz sonucunda, televizyon dizilerinin, izleyicilerin algıladıkları destinasyon imajı üzerindeki etkisinin "olumlu" olduğunu söyleyebiliriz.

Anahtar Kelimeler: Destinasyon Imajı, Televizyon Dizileri, Destinasyon Pazarlaması

\section{Abstract}

The TV series whose numbers increased recently and destinations which are placed in theseseries as a touristic product can be effective on the viewers' perception of destination image. The creation and strengthening of a positive image toward the destinations in which these series were shotare of great importance for city tourism.

The purpose of this study is to determine the effect of TV series on viewers' perceptions of destination image. The study, at the same time, includes a survey toward viewers who are older than 18 years old and who live in the center of Aydin Province.

\footnotetext{
${ }^{1}$ Bu çalışma 26-27 Nisan 2013 tarihinde Kuşadası'nda gerçekleştirilen International Conference on Business and Management'da sözlü olarak sunulan bildirinin gözden geçirilmiş ve genişletilmiş halidir.
} 
Various statistical analyses obtained from the survey results are also performed in thestudy. As a result of the analysis conducted, it can be said that TV series have a positive effect on the audience perception of destination image.

Key Words: destination image, television series, destination marketing

\section{GİRIŞ}

Popüler kültürün getirdiği önemli oluşumlardan biri olan dizi kültürü, günümüz izleyicileri üzerinde oldukça etkili olabilmektedir. Dizilerin konusu ve oyuncuları dışında dizinin çekildiği destinasyon da izleyicinin dikkatini çekebilmektedir. Günümüzde destinasyonların bir ürün gibi algılandığı ve dizilerin içine yerleştirildiğini görmek mümkündür. Dizide geçen destinasyonlar, diziler üzerinde olumlu bir imaj yaratarak diziler arasında farklılığa yol açarak, izleyicilerin ilgilerini dizi üzerine çekebilmektedir.

Bununla birlikte televizyon dizilerine konu olan destinasyonlar turizm ve pazarlama açısından da önemli bir katkı sağlamaktadır. Diğer bir taraftan, diziler destinasyonları büyük bir titizlikle seçmekte ve destinasyonların doğal güzelliklerini en iyi şekilde yansıtarak izleyici kitlesini oraya yönlendirmektedirler. TV dizilerine yönelik artan ilgi, pazarlamacılara, alternatif bir pazarlama iletişim aracı olarak dizilere ürün yerleştirmeyi kullanma olanağı sağlamıştır.

\section{DESTINASYON PAZARLAMASI}

Destinasyonlar, insanların seyahat ettikleri ve belli etkinliklerde bulunmak için konaklamayı tercih ettikleri yerlere verilen isimdir. Seyahatlerde ulaşmak istenen hedef bölge (destinasyon) kişi tarafından seyahatinde gitmeyi amaçladığ 1 ya da ulaşmak istediği nokta olarak seçilmiş, belirlenmiş yerdir (Yaraşl1, 2007:12).

Ülkeler açısından önemli bir turistik ürün olan destinasyonlara yönelik etkin pazarlama stratejilerinin geliştirilmesi; buraların ziyaretçiler tarafından bilinen, beğenilen ve tercih edilen yerler olması, rekabet açısından farklılaştırıcı bir güçtür. Destinasyonların marka haline getirilmesi ve dolayısıyla bir kimlik kazanması, turizm açısından oldukça önemlidir (Baloğlu ve McCleary, 1999:868). Potansiyel turistleri, ziyaret eden turistler haline getirme amac1 güden bir ülkenin veya bölgenin, turizm değerleri hakkında bilgi vererek görmeye ikna edecek nitelikteki çalışma ve çaba konusunda gereken önemi vermesi gerekmektedir (Şahbaz, 2000: 3).

Destinasyon pazarlamasının en önemli yollarından birisi dış tanıtım faaliyetleridir. Dış tanıtım, destinasyon hakkında olumlu bir imaj oluşturmak varsa yanlış düşünce ve önyargıları ortadan kaldırmak ve bütün bunların sonucunda bir ölçüde de olsa, ekonomik kazanç sağlamak amacıyla reklam, halkla ilişkiler, propaganda ve enformasyon gibi yöntemler kullanarak hedef kitlelere yöneltilen aydınlatıcı faaliyetler olarak tanımlanır (Duran, 2008:14).

Destinasyon imaj1, bireyin belirli bir destinasyona yönelik sahip olduğu bilgi ve duygusal düşünceleri olarak tanımlanabilir. Destinasyon imajı, turistin seyahat öncesi satın alma kararı üzerinde etkili olurken; destinasyonda geçirilen zamanın ve yaşanan deneyimin ise seyahat sonrası davranış ve tekrar ziyaret etme niyeti üzerinde etkili olduğu kabul edilir (Chen ve Tsai, 2007:1116). 
Destinasyon imaj1 çalışmaları ilk olarak Hunt'un (1975) turizm gelişiminde imajin rolünü test ettiği etkileyici çalışmasıyla başlamışıı. Daha sonraki yıllarda bu kavramı ele alan çalışmaların bir kısmı belirli destinasyonların, turistler tarafından algılanan imajlarını ölçmek üzerinde yoğunlaşmıştır. Diğer bir kısım çalışmalar ise, imaj algısını oluşturan etmenleri analiz edip kavramsal bir temel oluşturduktan sonra imaj algısını ölçmeye çalışmıştır (İpar, 2011:190).

Destinasyon imajı, sözkonusu destinasyonla ilgili olarak insanların inançlarının, fikirlerinin ve izlenimlerinin toplamı olarak tanımlanmakta ve bu imajın etkili olması, geçerliliğine, inandırıcılığına, basitliğine, çekiciliğine ve ayırıcı özelliğe sahip olmasına bağlanmaktadır (Yükselen ve Güler, 2009:23). İmaj yaratma ve yönetme işinin temelinde etkin iletişim bulunmaktadır. Verilmek istenen imaj doğru medya kanalları ile doğru yer ve zamanlarda verilerek etkinleştirilmelidir (Öter ve Özdağan, 2005:129).

Potansiyel ziyaretçilerin bir destinasyonu tercih etmeleri kararları üzerinde etkili olan destinasyon imajı çeşitli unsurların bir birleşeni olarak karşımıza çıkmaktadır. Kişinin deneyimlerinden, medyadan elde edilen bilgilere kadar uzanan bir geniş bir yelpaze içerisinde, nesne ile ilgili görülen, duyulan, okunan ve tecrübe edilen her şey imajın oluşumunda etkin rol oynamaktadır (Üner vd.,2006:191).

Yoğun rekabetin yaşandığı turizm sektöründe destinasyonları daha iyi tanıtma, olumlu bir imaj oluşturma, olumsuz bir imajı olumluya dönüştürme, rakiplerden daha iyi konumlandırma amacıyla destinasyonlar film yada dizilere bir ürün olarak yerleştirilmektedir. Düşük maliyetli bir pazarlama stratejisi olarak destinasyonların film ve dizilere bir ürün gibi konu olması son yıllarda öne çıkmaktadır (Yılmaz ve Yolal, 2008:188).

Destinasyon imajının en önemli rollerinden birisi, turistlerin karar alma süreçleri üzerindeki etkisidir. Çok sayıda araştırmacı, destinasyona ilişkin algılamalar ile satın alma kararları arasında olumlu yönde bir ilişki olduğu sunucunu vurgulamıştır. Turizm alanında gerçekleştirilen imaj araştırmaları, birkaç farklı bakış açısını yansıtmaktadır; destinasyon seçimi ile imaj arasındaki ilişki, imajın oluşum süreci, imajda değişiklik yapılması ve imajın ölçülmesi. Filmler ve TV dizileri, bu noktadaki temel bilgi kaynakları oldukları için, özellikle ikincil imajın oluşmasında oldukça etkin olabilmektedirler. "Temel imaj” ise, ziyaretin gerçekleşmesinden sonra ortaya çıkmaktadır ( Şahbaz ve K1lıçlar, 2009:5).

\section{DESTINASYON PAZARLAMASINDA TELEVIZYON DİZILERININ ROLÜ}

Filmler, TV programları ve dizilerin içine destinasyon yerleştirmek, geleneksel pazarlama çabaları ile kolaylıkla ulaşılamayacak bir farkındalık yaratan ve uzun dönemli etki sağlayan bir çalışmadır. Pazarlamanın bu biçimi destinasyonlara olumlu bir imaj kazandırır ve ziyaretçi sayılarında gözle görülür bir artış sağlar (Saltık, Coşar ve Kozak, 2010:43).

$\mathrm{Bu}$ açıdan değerlendirildiğinde, günümüzde TV dizileri ve filmler bireylerin belirli bir destinasyona ilişkin düşüncelerini ve algılamalarını olumlu ya da olumsuz şekilde etkileyebilen önemli bir pazarlama iletişim aracı konumuna gelmiştir. Algılamaların olumlu yönde gerçekleşmesi sözkonusu destinasyonlara yönelik ziyaret etme talebini de olumlu yönde etkileyecektir.

Filmler ve televizyon dizileri potansiyel turistlere destinasyon ve onun çekicilik yaratan özellikleri ile ilgili bilinirlik sağlamaktadır. Potansiyel turistler destinasyona gitmeden ve dolayısı ile ilk elden bir tecrübe yaşamadan, destinasyonla ilgili bilgi, fikir ve imaj sahibi olabilmektedirler. Olumlu imajın oluşturulmasında filmler ve televizyon dizileri bu noktada da önemli faktörlerdendir (O’Connor, Flanagan ve Gilbert, 2008:424).

Bir destinasyonun marka imajının güçlendirilmesinde, bu yerin sahip olduğu olanakların sunduğu hizmet kalitesinin de iyileştirilmesi gerekmektedir. Altyapının iyi olması; doğal ve tarihi güzelliklerin korunmasi; yeme, içme, eğlence ve konaklama hizmetlerinin turistleri memnun edecek düzeyde olması, sözkonusu destinasyonun farkındalık yaratmasında etkili olmaktadır. Örneğin, ülkemizde 2002 yılında çekilen Asmalı Konak dizisi Nevşehir turizmini etkilemiş ve Nevşehir'in tanıtımında önemli rol oynamıştır. Bu dönemde Nevşehir'e düzenlenen geziler belli bir oranda artmıştır. Yine aynı 
şekilde, 2013 yılında da devam eden Yer Gök Aşk dizisi de Nevşehir- Ürgüp Göreme'de çekilmiştir. Günümüzde, ülkemizde tarihi, ekonomik, kültürel ve turizm potansiyeline sahip bir çok destinasyon benzer şekilde farklı TV dizilerine bir ürün olarak yerleştirilmektedir.

\section{UYGULAMA}

\subsection{Araştırmanın Amacı}

$\mathrm{Bu}$ araştırmanın amacı, televizyon dizilerinin destinasyon imajı üzerine etkilerini ortaya koymaktır. Destinasyon imaj1, potansiyel ziyaretçilerin destinasyon seçiminde ve sözkonusu destinasyonu değerlendirmeleri sürecinde önemli bir faktördür. Çalışmada, Aydın il merkezinde yaşayan 18 yaş üstü TV dizisi izleyicilerine yönelik bir alan araştırmasına yer verilmiştir. Anket verilerinden yararlanılarak TV dizisi izleyicilerinin destinasyon imajı algılamaları ölçülmeye çalışılmıştır.

\subsection{Araştırmanın Yöntemi}

Araştırma, Aydın il merkezinde yaşayan dizi seyircilerine yönelik anket çalışmasını içermektedir. Anket soru formunun oluşturulmasında, Yılmaz ve Yolal (2008) "Film Turizmi: Destinasyonların Pazarlamasında Filmlerin Rolü" konulu çalışması ile Şahbaz ve Kılıçlar (2009) "Filmlerin ve Televizyon Dizilerinin Destinasyon İmajina Etkileri" konulu çalışmasından yararlanılmıştır. Televizyon izleyicilerinin dizilerde geçen destinasyonlara yönelik algılamalarını ortaya koyabilmek için toplam 38 adet soru sorulmuştur. Anketin birinci bölümünde, ankete katılanların demografik yapılarını değerlendirebilmek amacıyla, sekiz adet soru yöneltilmiştir. Anketin ikinci bölümünde ise (9. ve 38. sorularda), ankete katılanların, TV dizilerinin destinasyon imajına yönelik algılamalarını ölçmeye yönelik ifadeler yer almaktadır. Değerlendirme 5'li likert ölçeği aracıllğ ile gerçekleştirilmiştir. Ölçekte 5"kesinlikle katılıyorum", 1 ise "kesinlikle katılmıyorum"a karşılık gelmektedir.

Araştırma örnekleminin belirlenmesinde, basit örnekleme yöntemlerinden, basit rassal örnekleme yöntemi kullanılmıştır. Çalışmanın ana kütlesini Aydın il merkezinde yaşayan 18 yaş üstü bireyler temsil etmektedir. \%95 güven düzeyinde örneklem sayısı (n) 385 kişi olarak hesaplanmıştır. Bazı anketlerin değerlendirme dışı bırakılabileceği olasılığına karşın, bu sayının üstüne çıkılarak 406 kişiye anket uygulanmıştır. Anket çalışması Aydın merkezde yaşayan rastgele seçilmiş 18 yaş üstü kişilerin, TV dizilerindeki destinasyonlara yönelik algılamalarını ortaya koymak amacıyla gerçekleştirilmiştir.

\subsection{Analiz ve Sonuçlar}

\subsubsection{Güvenilirlik Analizi}

İlk olarak güvenilirlik analizi yapılmıştır. Güvenilirlik analizi, ölçmede kullanılan testlerin, anketlerin ya da ölçeklerin özelliklerini ve güvenilirliklerini değerlendirmek üzere geliştirilmiş bir yöntemdir. Araştırmada güvenilirlik analizinde kullanılan modellerden Alfa modeli kullanılmıştır. Bu yöntem, ölçekte yer alan soruların homojen bir yapı gösteren bir bütünü ifade edip etmediğini araştırır (Kalayc1, 2009: 405).

Anket çalışmasına ilişkin güvenilirlik analizi sonucu, Tablo 1'de yer almaktadır. 
Tablo 1: Güvenilirlik Analizi

\begin{tabular}{|l|l|r|l|c|}
\hline & $\mathrm{N}$ & \multicolumn{1}{|l|}{ Yüzde } & Crohnbach alpha & N of İtems \\
\hline Valid & 353 & 86,9 & 0.783 & 38 \\
Excluded & 53 & 13,1 & & \\
Total & 406 & 100 & & \\
\hline
\end{tabular}

Ankette yer alan toplam otuz sekiz sorunun tümüne güvenilirlik analizi uygulanmıştır. Tablo 1'de görüldüğü gibi analiz sonucunda, Cronbach Alpha değerinin 0,783 olduğu anlaşılmaktadır. Buna göre, Cronbach Alpha katsayısının 0,783 olması güvenirliliğinin kabul edilebilir düzeyde olduğu ve elde edilen verilerin güvenilir olduğunu ifade eder. Bu bilgilere göre ölçek güvenilir bir ölçektir.

\subsubsection{Frekans Tabloları}

Anket çalışmasında karşılıklı görüşme ile 406 katılımcıdan cevap alınmıştır. Ankete katılan kişilerin demografik özellikleri Tablo 2'de yer almaktadır.

Tablo 2: Demografik Özelliklerin Frekans ve Dağılımları

\begin{tabular}{|c|c|c|c|c|c|c|c|}
\hline \multicolumn{2}{|c|}{ Demografik Özellikler } & \multirow{2}{*}{$\begin{array}{l}\mathbf{f} \\
243 \\
163\end{array}$} & \multirow{2}{*}{$\begin{array}{l}\% \\
59,9 \\
40,1\end{array}$} & \multicolumn{2}{|c|}{ DemografikÖzellikler } & \multirow{2}{*}{$\begin{array}{l}\mathbf{f} \\
142 \\
217\end{array}$} & \multirow{2}{*}{$\begin{array}{l}\% \\
35,0 \\
11,6\end{array}$} \\
\hline : & $\begin{array}{l}\text { Bayan } \\
\text { Bay }\end{array}$ & & & 总 & $\begin{array}{l}\text { Bekar } \\
\text { Evli }\end{array}$ & & \\
\hline$\stackrel{\pi}{\star}$ & $\begin{array}{l}\quad 18-29 \\
30-39 \\
40-49 \\
50-59 \\
60 \text { veüzeri }\end{array}$ & $\begin{array}{l}85 \\
105 \\
115 \\
64 \\
37\end{array}$ & $\begin{array}{l}20,9 \\
25,9 \\
28,3 \\
15,8 \\
9,1\end{array}$ & 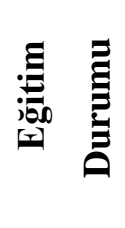 & $\begin{array}{l}\text { İlköğretim } \\
\text { Lise } \\
\text { Üniversite } \\
\text { YüksekLisans } \\
\text { Doktora }\end{array}$ & $\begin{array}{c}40 \\
177 \\
165 \\
15 \\
6\end{array}$ & $\begin{array}{l}9,9 \\
43,6 \\
40,6 \\
3,7 \\
1,5\end{array}$ \\
\hline$\frac{\frac{4}{0}}{\frac{0}{0}}$ & $\begin{array}{l}\text { İşçi } \\
\text { Memur } \\
\text { Ev Hanımı } \\
\text { SerbestMeslek } \\
\text { Öğrenci } \\
\text { Emekli }\end{array}$ & $\begin{array}{l}16 \\
82 \\
57 \\
96 \\
71 \\
54\end{array}$ & $\begin{array}{l}3,9 \\
20,2 \\
14,0 \\
23,6 \\
17,5 \\
13,3\end{array}$ & 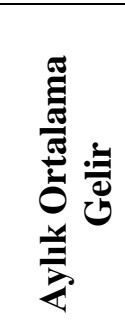 & $\begin{array}{ll} & 100 \mathrm{TL} \text { 'den } \\
\text { az } & 1001-1500 \\
\mathrm{TL} & 1501-2000 \\
\mathrm{TL} & 2001-2500 \\
\text { TL } & 2501 \mathrm{TL} \text { ve } \\
\text { fazla }\end{array}$ & $\begin{array}{c}67 \\
94 \\
115 \\
52 \\
57\end{array}$ & $\begin{array}{l}16,5 \\
23,2 \\
28,3 \\
12,8 \\
14,0\end{array}$ \\
\hline & & & & & Toplam & 406 & 100 \\
\hline
\end{tabular}

Ankete katılanların çoğunluğu kadın olup, genç yaş aralığındadır. Eğitim düzeyine baktığımızda lise ve üniversite mezunları çoğunluğu temsil etmektedir. Meslek grupları açısından memur ve serbest meslek grubu daha fazla orandadır, aylık ortalama 2000TL gelir düzeyine sahiptir.

\subsubsection{Hipotez Testi}

Çalışmanın bu bölümünde, ankete katılanların, TV dizilerinin destinasyon imajı üzerine etkisi konusunda algılamalarını belirlemeye yönelik on iki hipotez geliştirilmiştir. Buna göre parametrik testlerden hipotez testi uygulanmış ve sonuçlar aşağıdaki Tablo 3 'de verilmiştir. 
Tablo 3. Hipotez Testi Sonuçları

\begin{tabular}{|c|c|}
\hline \multicolumn{1}{|c|}{ Oluşturulan Alternatif Hipotezler } & Sig. (2-tailed) \\
\hline H:1Bir destinasyonun marka imajının güçlenmesinde TV dizileri etkilidir. &, 000 \\
\hline H:2Televizyon dizilerinin geçtiği destinasyonlar ilgimi çeker &, 000 \\
\hline $\begin{array}{c}\text { H:3 Televizyon dizilerinde gördüğüm destinasyonları merak edip, gidip } \\
\text { görmek isterim. }\end{array}$ &, 000 \\
\hline H:4Televizyon dizilerinde geçen destinasyonları bilmek isterim. &, 000 \\
\hline $\begin{array}{c}\text { H:5Gittiğim bir destinasyonu dizilerde gördüğüm zaman yeniden gitmek } \\
\text { isterim. }\end{array}$ &, 000 \\
\hline H:6Dizilerde geçen destinasyona dikkat ederim. &, 000 \\
\hline H:7Dizilerin konusu destinasyonun imajını olumlu ya da olumsuz etkiler. &, 000 \\
\hline $\begin{array}{c}\text { H:8TV dizisinin konusu, o dizide görülen destinasyonu ziyaret etme } \\
\text { isteğimi etkiler. }\end{array}$ &, 000 \\
\hline H:9Dizide yer alan destinasyon çekici ise tercih ederim. &, 000 \\
\hline $\begin{array}{c}\text { H:10TV dizilerinin, insanların belirli bir destinasyonu tanımalarında etkisi } \\
\text { büyüktür. }\end{array}$ &, 000 \\
\hline $\begin{array}{c}\text { H:11TV dizilerinin turizm potansiyeline sahip yerlerde çekilmesi, o } \\
\text { bölgenin turistik bir destinasyon olmasında olumlu katkı yaratır. }\end{array}$ &, 000 \\
\hline H:12Bir destinasyonun marka imajının güçlenmesinde TV dizileri etkilidir. &, 000 \\
\hline
\end{tabular}

*Ölçek 1. Kesinlikle Katılmıyorum-5 KesinlikleKatılıyorum

$* * \mathrm{p}<0,05$ (Alternatif H1 Hipotezikabul)

Hipotez testi tablosundaki Sig. (2-tailed) değerlerine bakıldığında, p değerlerinin 0,05'ten küçük olduğu görülmektedir. Buna gore alternatif hipotezler "Kabul" edilmektedir. Kabul edilen alternatif hipotezler Tablo 3'de yer almaktadır. Ankete katılan TV izleyicilerinin, TV dizilerinde geçen destinasyonlara ilgi duyduklarl; dizide geçen destinasyonlara dikkat ettikleri; merak edip gidip görmek istedikleri; bu tür dizilerin destinasyonun marka imajını güçlendirdiği sonuçları hipotez testi sonucunda elde edilmiştir. Sonuç olarak, "televizyon dizilerinin, izleyicilerin algıladıkları destinasyon imaj1 üzerindeki etkisinin olumlu" olduğunu söyleyebiliriz.(0.00 sonucu Ho hipotezinin Red, H1 hipotezinin Kabul edildiğini gösteriyor)

\subsection{4. Çapraz Tablolar}

Çalışmanın bu bölümünde ise ankete katılanların eğitim durumu, gelir düzeyi ve cinsiyetleri ile destinasyon imajı konusundaki algılamalarına yönelik bazı ifadeler arasındaki ilişkiyi görebilmek amaciyla çapraz tablolar oluşturulmuştur. 
Tablo 4: Bir Destinasyonun Marka İmajının Güçlenmesinde TV Dizileri Etkilidir İfadesi ile Eğitim Durumu Arasındaki Çapraz Tablo

\begin{tabular}{|c|c|c|c|c|c|c|}
\hline & \multicolumn{6}{|c|}{ Eğitim Durumu } \\
\hline \multirow{6}{*}{\begin{tabular}{l}
\multicolumn{1}{c}{ Bir } \\
destinasyonun \\
marka imajının \\
güçlenmesinde \\
TV dizileri \\
etkilidir.
\end{tabular}} & & İlköğretim & Lise & Üniversite & $\begin{array}{l}\text { Yüksek } \\
\text { Lisans }\end{array}$ & Doktora \\
\hline & $\begin{array}{l}\text { Kesinlikle } \\
\text { Katılmiyorum }\end{array}$ & $35,3 \%$ & $11,8 \%$ & $52,9 \%$ & $0 \%$ &, $0 \%$ \\
\hline & Katılmiyorum & $11,8 \%$ & $49,0 \%$ & $31,4 \%$ & $3,9 \%$ & $3,9 \%$ \\
\hline & $\begin{array}{l}\text { Kararsızım/Fikrim } \\
\text { Yok }\end{array}$ & $3,8 \%$ & $43,2 \%$ & $46,2 \%$ & $4,5 \%$ &, $8 \%$ \\
\hline & Kat1lyyorum & $10,3 \%$ & $42,1 \%$ & $42,1 \%$ & $2,8 \%$ & $2,1 \%$ \\
\hline & $\begin{array}{l}\text { Kesinlikle } \\
\text { Katıllyorum }\end{array}$ & $14,7 \%$ & $52,9 \%$ & $23,5 \%$ & $8,8 \%$ &, $0 \%$ \\
\hline
\end{tabular}

Tablo 4'deki veriler incelendiğinde, üniversite mezunlarının \%52,9'u 'bir destinasyonun marka imajının güçlenmesinde TV dizileri etkilidir' görüşüne kesinlikle katılmadıklarını belirtirken; lise mezunlarının \%52,9'u bu görüşe kesinlikle katıldıkları görülmektedir.

Tablo 5: Televizyon Dizilerinde Gördüğüm Destinasyonları Merak Edip, Gidip Görmek İsterim İfadesi ile Aylık Toplam Gelir Arasındaki Çapraz Tablo

\begin{tabular}{|c|c|c|c|c|c|c|}
\hline & \multicolumn{6}{|c|}{ Ailenize Giren Aylık Toplam Gelir } \\
\hline \multirow{6}{*}{$\begin{array}{l}\quad \text { Televizyo } \\
\text { n dizilerinde } \\
\text { gördüğüm } \\
\text { destinasyonları } \\
\text { merak edip, } \\
\text { gidip görmek } \\
\text { isterim. }\end{array}$} & & $\begin{array}{l}1000 \text { ve } \\
\text { daha az }\end{array}$ & $1001-1500$ & $1501-2000$ & $2001-2500$ & $\begin{array}{l}2501 \text { ve } \\
\text { üzeri }\end{array}$ \\
\hline & $\begin{array}{l}\text { Kesinlikle } \\
\text { Katılmıyorum }\end{array}$ &, $0 \%$ & $44,4 \%$ & $11,1 \%$ &, $0 \%$ & $44,4 \%$ \\
\hline & Katılmiyorum & $5,9 \%$ & $20,6 \%$ & $41,2 \%$ & $23,5 \%$ & $8,8 \%$ \\
\hline & $\begin{array}{l}\text { Kararsizım/Fikrim } \\
\text { Yok }\end{array}$ & $22,6 \%$ & $26,2 \%$ & $28,6 \%$ & $8,3 \%$ & $14,3 \%$ \\
\hline & Kat1lyyorum & $16,4 \%$ & $24,0 \%$ & $31,1 \%$ & $13,1 \%$ & $15,3 \%$ \\
\hline & $\begin{array}{l}\text { Kesinlikle } \\
\text { Kat1liyorum }\end{array}$ & $27,1 \%$ & $20,8 \%$ & $22,9 \%$ & $18,8 \%$ & $10,4 \%$ \\
\hline
\end{tabular}

Tablo5'te aileye giren aylık toplam gelir ile "televizyon dizilerinde gördüğüm destinasyonları merak edip, gidip görmek isterim" ifadesi arasındaki ilişki incelenmiştir. 2501 TL ve daha fazla gelire sahip olan katılımcılar, bu görüşe kesinlikle katılmadıklarını belirtmişlerdir. Aylık geliri 1000TL ve daha az olan katılımcılar ise \%27,1 oranıyla bu görüşe kesinlikle katıldıklarını belirtmişlerdir. 
Tablo 6: "Dizilerde Geçen Destinasyona Dikkat Ederim" ile "Cinsiyet" Arasındaki Çapraz Tablo

\begin{tabular}{|c|c|c|c|}
\hline \multicolumn{4}{|c|}{ Cinsiyetiniz } \\
\hline \multirow{6}{*}{$\begin{array}{l}\text { Dizilerde } \\
\text { geçen } \\
\text { destinasyona } \\
\text { dikkat ederim. }\end{array}$} & & Kadın & Erkek \\
\hline & $\begin{array}{l}\text { Kesinlikle } \\
\text { Kat1lmiyorum }\end{array}$ & $30,0 \%$ & $70,0 \%$ \\
\hline & Katılmıyorum & $70,0 \%$ & $30,0 \%$ \\
\hline & $\begin{array}{l}\text { Kararsizım/Fikrim } \\
\text { Yok }\end{array}$ & $61,2 \%$ & $38,8 \%$ \\
\hline & Katıliyorum & $59,9 \%$ & $40,1 \%$ \\
\hline & $\begin{array}{l}\text { Kesinlikle } \\
\text { Kat1liyorum }\end{array}$ & $71,4 \%$ & $28,6 \%$ \\
\hline
\end{tabular}

Cinsiyet ile dizilerde geçen destinasyona yönelik dikkat arasındaki ilişki Tablo 6'da açıklanmıştır. Erkek katılımcıların \%70’i bu görüşe kesinlikle katılmadıklarını; kadın katılımcıların ise \%71,4'ü bu görüşe kesinlikle katıldıklarını belirtmiş̧lerdir.

\section{SONUÇ}

Günümüzde, TV dizilerinin çekildiği mekanlar, konaklar, oteller ve diğer yerler dizinin yarattığı ilgiye göre turistik açıdan dikkat çekici destinasyonlar haline gelebilmektedir. Destinasyonların bu şekilde TV dizilerine bir ürün olarak yerleştirilmesi, destinasyon pazarlaması açısından giderek tercih edilen bir pazarlama çabası olarak dikkat çekmektedir. TV dizilerindeki artış ve bunlara yönelik artan izleyici ilgisi karşısında; destinasyonların bir ürün olarak yerleştirilmesi, destinasyon imajının güçlendirilmesinde etkili bir pazarlama iletişimi aracı olduğu düşünülmektedir. Destinasyon pazarlamasında, turistlerin her konuda memnuniyetlerinin sağlanması önemli bir başarıdır. Böylelikle, destinasyonun marka imajının güçlendirilmesinde, turistlerin tekrar ziyaret etme isteklerinde ve çevresindeki kişilere sözkonusu destinasyonunu tavsiye etme davranışlarında olumlu bir etkisi olacaktır.

Aydın il merkezinde yaşayan 18 yaş üstü TV dizisi izleyicilerinin, destinasyon imajına yönelik algılamalarını ölçmeye yönelik bu çalışmada, televizyon dizilerinin, izleyicilerin algıladıkları destinasyon imajı üzerindeki etkisinin olumlu" olduğu belirlenmiştir. Ankete katılan TV izleyicilerinin, TV dizlerilerinde geçen destinasyonlara ilgi duydukları; dizi de geçen destinasyonlara dikkat ettikleri; merak edip gidip görmek istedikleri; bu tür dizilerin destinasyonun marka imajını güçlendirdiği sonuçları da geliştirilen hipotezlerin testi sonucunda elde edilmiştir.

Sonuç olarak, turizm potansiyeline sahip destinasyonların imajlarına yönelik gerekli çalışmaların yapılması son derece önemlidir. Türkiye'de insanların dikkatini çeken TV dizilerine konu olan destinasyonların o dönem içinde popüleritesinin arttığını söyleyebiliriz. Bu tür destinasyonlara gerekli turistik tesislerin yapılması yada mevcut olanların fiziki koşullarının iyileştirilmesi; yöresel turistik ürünlerle çeşitlendirilmesi yöre ziyaretçilerinin memnuniyetlerini arttırıcı etki yaratacaktır. Sözkonusu destinasyonun imajının güçlendirilmesine yönelik yapılacak tanıtım çabaları, ziyaretçileri bu bölgeye tekrar çekebileceği gibi çevresindekilere yönelik olumlu tavsiyeleri de beraberinde getirecektir. 


\section{KAYNAKÇA}

BALOĞLU S.andMcCLEARY K. W., (1999), A Model of Destination Image Formation Annals Of Tourism Research, Vol. 26, No. 4, pp. 868-897.

CHİNG-FU C.;DUNGcHUN T., (2007), "How destination image and evaluative factors affect behavioral intentions?", Tourism Management, 28; 1115-1122; 2007.

DURAN, N. (2008), Destinasyon Tanımında Resmi Web Siteleri: Türkiye'nin Rakip Destinasyonlarının Web Sitelerinin Değerlendirmesine Yönelik Bir Araştırma, Yüksek Lisans Tezi, Adnan Menderes Üniversitesi Sosyal Bilimler Enstitüsü: Aydın.

IPAR, M.S. (2011), Destinasyon Markalaşması ve İstanbul Üzerine Bir Uygulama, Yüksek Lisans Tezi, Balıkesir Üniversitesi Sosyal Bilimler Enstitüsü: Balıkesir.

KALAYCI, Ş. (2009), SPSS Uygulamalı Cok Değiskenli İstatistik Teknikleri (4. Baskı), Asil Yayın Dağıtım Ltd. Sti.: Ankara.

O'CONNOR, N.; FLANAGAN, S.; ve GILBERT, D., (2008), “The Integration of Filminduced Tourism Destination and Branding in Yorkshire, UK" International Journal of Tourism Research, 10(5): 423-437.

ÖTER, Z.; ÖZDOĞAN, O.N., (2005), “Kültür Amaçlı Seyahat Eden Turistlerde Destinasyon İmajı: Selçuk-Efes Örneği”,Anatolia: Turizm Araştırmaları Dergisi, Cilt 16, Sayı 2, Güz: $127-138$.

SAHPAZ, P.(2000), “ Türkiye'nin Tanıtım Harcamalarının Dış Turizm Talebine Etkileri”, Dokuz Eylül Üniversitesi Sosyal Bilimler Enstitüsü Dergisi, cilt:2, sayı:3, 1-19.

ŞAHBAZ, R. P.; KILIÇLAR, A.(2009), "Filmlerin ve Televizyon Dizilerinin Destinasyon İmajına Etkisi”, İşletme Araştırmaları Dergisi, c.1, s.1, ss.31-52.

SALTIK, I.A.; COŞAR, Y.; Kozak, M.(2010), “Televizyon Dizilerinin Destinasyon Pazarlaması Açısından Olası Sonuçları", Anatolia Turizm Araştırmaları Dergisi,c.21, s.1, ss.41-50. 
YARAŞLI, G.Y.(2007),Destinasyon İmajı ve Trabzon Yöresine Dönük Bir Çalışma, Yüksek Lisans Tezi, Başkent Üniversitesi Sosyal Bilimler Enstitüsü:Ankara.

YILMAZ, H.; YOLAL, M. (2008), "Film Turizmi: Destinasyonların Pazarlanmasında Filmlerin Rolü”, Anadolu University Journal of Social Sciences, Vol:8,Sayı:1, 175-192.

YÜKSELEN C.; GÜLER G. E., (2009), Antakya Marka Kent Görüş ve Öneriler, Detay Yayıncilık, Ankara, 2009.

ÜNER, M.M.;GÜÇER, E.; TAŞÇI, A., (2006), “Türkiye Turizminde Yükselen Destinasyon Olarak İstanbul Şehrinin İmajı”, Anatolia: Turizm Araştırmaları Dergisi, Cilt 17, Sayı 2 , Güz:189-201. 